\title{
Leitura e escrita de gêneros discursivos na pequena infância: um estudo na perspectiva bakhtiniana
} Reading and writing of discursive genres in early childhood: a study in the bakhtinian perspective

\section{Lectura y escritura de géneros discursivos en la pequeña infancia: un estudio en la perspectiva bakhtiniana}

Greice Ferreira da Silva ${ }^{1}$

DOI: http://dx.doi.org/10.20435/serie-estudos.v23i49.1137

\begin{abstract}
Resumo: Este artigo objetiva discutir a formação do leitor e do re-criador de gêneros discursivos na Educação Infantil. Para tanto, aborda o conceito de linguagem, de leitura e de gênero discursivo ancorada no arcabouço teórico do Círculo de Bakhtin na tentativa de contribuir com o trabalho pedagógico do professor e no processo de apropriação e objetivação da língua materna pelas crianças pequenas. Essas reflexões remetem ao entendimento da aprendizagem do ato de ler, como uma prática histórica e culturalmente constituída, e à leitura, como o lugar de encontro do leitor com as vozes alheias. O estudo refere-se à parte de uma pesquisa qualitativa realizada com uma turma de crianças de 4 e 5 anos numa escola pública municipal de uma cidade do interior do estado de São Paulo. Trata-se de uma pesquisa-ação, e a tese que norteia este trabalho é a de que as crianças aprendem a língua desde a Educação Infantil por meio dos gêneros discursivos - uma vez que a língua se manifesta pelos gêneros - quando o professor introduz o ensino dos gêneros na escola como instrumento de humanização, como forma de apropriação da cultura humana. A proposta centra-se na criança como sujeito social, sujeito de suas aprendizagens, capaz de estabelecer relações dialógicas e dinâmicas com os gêneros discursivos e seus elementos constitutivos.
\end{abstract}

Palavras-chave: leitura e escrita; gêneros discursivos; Educação Infantil.

Abstract: This article aims to discuss the formation of the reader and the re-creator of discursive genres in Early Childhood Education. In order to do so, it addresses the concept of language, reading and discursive gender anchored in the theoretical framework of the Circle of Bakhtin in an attempt to contribute to the pedagogical work of the teacher and in the process of appropriation and objectification of the mother tongue by young children. These reflections refer to the understanding of learning to read as a historical and culturally constituted practice and reading as the meeting place of the reader with the voices of others. The study refers to the part of a qualitative research

\footnotetext{
${ }^{1}$ Universidade Estadual de Londrina (UEL), Londrina, Paraná, Brasil.
} 
carried out with a group of children of 4 and 5 years old in a municipal public school of a city in the interior of the state of São Paulo. It is an action research and the thesis that guides this work is that children learn the language from Child Education through the discursive genres- once the language is manifested by the genres- when the teacher introduces the teaching of the genres in the school as an instrument of humanization, as a form of appropriation of human culture. The proposal focuses on the child as a social subject, subject of their learning, able to establish dialogic and dynamic relations with the discursive genres and their constituent elements.

Keywords: reading and writing; discursive genres; Early Childhood Education.

Resumen: Este artículo objetiva discutir la formación del lector y del re-creador de géneros discursivos en la Educación Infantil. Para ello, aborda el concepto de lenguaje, de lectura y de género discursivo anclado en el marco teórico del Círculo de Bakhtin en el intento de contribuir con el trabajo pedagógico del profesor y en el proceso de apropiación y objetivación de la lengua materna por los niños pequeños. Estas reflexiones remiten al entendimiento del aprendizaje del acto de leer como una práctica histórica y culturalmente constituida y la lectura como el lugar de encuentro del lector con las voces ajenas. El estudio se refiere a la parte de una investigación cualitativa realizada con una clase de niños de 4 y 5 años en una escuela pública municipal de una ciudad del interior del estado de São Paulo. Se trata de una investigación-acción y la tesis que orienta este trabajo es que los niños aprenden la lengua desde la Educación Infantil a través de los géneros discursivos-una vez que la lengua se manifiesta por los géneros- cuando el profesor introduce la enseñanza de los géneros en la escuela como instrumento de humanización, como forma de apropiación de la cultura humana. La propuesta se centra en el niño como sujeto social, sujeto de sus aprendizajes, capaz de establecer relaciones dialógicas y dinámicas con los géneros discursivos y sus elementos constitutivos.

Palabras clave: lectura y escritura; los géneros discursivos; Educación Infantil.

\section{INTRODUÇÃO}

As discussões e pesquisas sobre as práticas de leitura e de escrita na Educação Infantil se tornam cada vez mais presentes numa posição de considerável destaque nos debates referentes à educação das crianças pequenas. Observa-se uma preocupação generalizada entre educadores quando o assunto envolve tais práticas, o que faz subsistir entre eles a ideia de que ler e escrever são habilidades adquiridas por meio de treinos de escrita - cópias, exercícios de coordenação motora, repetição de nomes das letras e das sílabas (BISSOLI, 2009).

A despeito das pesquisas e de iniciativas que se contrapõem a essas práticas, há profissionais que insistem em limitar a formação de leitores e de re-criadores ${ }^{2}$ de

\footnotetext{
${ }^{2}$ Neste trabalho, optei por utilizar a expressão re-criador de gêneros discursivos, por entender que a criança, ao re-criar gêneros discursivos, cria-os e recria-os a partir do que já foi criado e apropriado da cultura humana. Entende-se que o ato de escrever está diretamente relacionado
} 
gêneros discursivos ainda na Educação Infantil, ao proporem exercícios de escrita enfadonhos e desvinculados da realidade, da vida e dos interesses infantis. Esse fato causa um distanciamento para a criança perceber a língua em seu funcionamento, estabelecer relações com ela e por meio dela e ser capaz de usá-la nos mais diversos contextos da sua realização concreta, nas diferentes formas de comunicação verbal que o sistema em uso permite realizar. Diante disso, o ensino da escrita nem sempre tem calcado o seu objeto como linguagem escrita, o que, consequentemente, faz com que o foco recaia nos aspectos formais do sistema linguístico.

Essas considerações trazem outro problema, com o pretexto de evitar uma possível desmotivadora experiência com textos cuja compreensão estaria, supostamente, para além das possibilidades das crianças pequenas, evidenciando um conceito de criança, de educação, de ensino e de aprendizagem empobrecidos, continuam a ser apresentados a elas textos simplificados, artificiais, cartilhescos, seguidos por exercícios que não possibilitam que a criança se insira e participe da cultura escrita pela principal via: a do significado e do sentido (LEONTIEV, 1978).

Este artigo é parte de uma pesquisa qualitativa (2013) que discute a formação de leitores e re-criadores de gêneros discursivos na Educação Infantil, na perspectiva bakhtiniana. Para tanto, a tese que norteia este trabalho é a de que as crianças aprendem a língua desde a Educação Infantil por meio dos gêneros uma vez que a língua se manifesta pelos gêneros - quando o professor introduz o ensino dos gêneros na escola como instrumento de humanização, como forma de apropriação da cultura humana.

Ao tratar sobre os gêneros discursivos na escola, desde a Educação Infantil considero que:

Não dá para higienizar essa perspectiva com o trabalho com a linguagem. Não dá para deixar a vida de lado. Se isso acontecer, perdemos a possibilidade de pensar em "gêneros do discurso", porque não teremos mais a linguagem funcionando como "correias de transmissão entre a história da sociedade

\footnotetext{
ao processo de apropriação da cultura humana e das experiências de que a criança participa. A opção pelo uso dessa expressão também se justifica pela tentativa de estar em consonância com os pressupostos teóricos assumidos neste trabalho. Pensar em re-criador de gêneros discursivos é entender que o tão absolutamente novo é tão inconcebível como o absolutamente mesmo (BAKHTIN, 1992; 2003). Nessa perspectiva, compreende-se a língua como algo vivo, em movimento, que se dá nas relações sociais, na interação com o outro, como criação da história e da cultura humanas, que se renovam e se reconstroem.
} 
e a história da linguagem" (BAKHTIN, 2003, p. 268). Não é porque estamos na escola que vamos inventar um trabalho com a linguagem que dispense não refletir "de modo mais imediato, preciso e flexível todas as mudanças que transcorrem na vida social" (idem, p. 268). A escola das nuvens, lugar de formação de um não-lugar, tem que ser destruída, e ceder lugar a uma escola onde cabe a vida. (GRUPO DE ESTUDOS DOS GÊNEROS DO DISCURSO [GEGe], 2010, p. 47).

Mas o que é formar o leitor e o re-criador de textos, na Educação Infantil? Como isso acontece, na escola da pequena infância ${ }^{3}$ ? Este trabalho busca responder a essas perguntas, na medida em que tenta compreender como a criança pode participar ativamente da cultura escrita, desde a Educação Infantil, e estabelecer relações intensas com essa cultura. Esse argumento não se coaduna com a escolarização precoce da criança, mas sugere pensar em formas de se garantir a ela as vivências necessárias e adequadas, na escola de Educação Infantil, a interação dinâmica com a língua em seu funcionamento e o diálogo com o escrito.

Na medida em que a criança vivencia a experiência dos objetos da cultura escrita, os modos como os seus gêneros são organizados, é que encontrará sentido nela. A condição de participação na cultura escrita está intimamente relacionada tanto a discursos que se elaboram em diferentes instituições e em práticas sociais orais e escritas, quanto a muitos objetos, procedimentos, atitudes, como formas sociais de expressão, entre elas a expressão em língua escrita (GOULART, 2006, p. 450). Assim, é possível pensar que é na Educação Infantil que as crianças devem iniciar esse processo de inserção e participação na cultura escrita, e é na escola da pequena infância que se deve pensar nos modos de se promover vivências para essa inserção e participação ocorrerem de maneira necessária e adequada.

O processo de apropriação e o de objetivação da língua escrita são, na essência, um único processo: o de internalização da língua em seu funcionamento, como conjunto sígnico de interação entre as pessoas. Nessa perspectiva, não se dicotomizam alfabetização e letramento como dois processos separados, mas como um processo discursivo interativo para a humanização das crianças. Ao se tratar da formação leitora e escritora de textos na Educação Infantil, vale ressaltar que a criança aprende de uma forma específica em cada idade. Para aprender, é preciso que seja ativa nesse processo, sujeito de suas aprendizagens.

\footnotetext{
${ }^{3}$ Por pequena infância refiro-me às crianças de 0 a 6 anos que compõem a Educação Infantil.
} 


\section{ASPECTOS DA TEORIA BAKHTINIANA E O ENSINO DA LÍNGUA COM AS CRIANÇAS PEQUENAS}

É no encontro do eu com o outro que o sujeito se constitui. É na relação do sujeito com os gêneros do discurso, com o professor, com seus pares, com a cultura, que a criança pequena inicia esse processo de apropriação da língua. É na alteridade que o sujeito se reconhece como tal, "que nos põe diante da inescapável busca/encontro com o Outro, desde o 'outro-de-mim' até o Outro que 'não sou eu' (MIOTELLO, 2012, p. 12).

Esse processo de participação da criança na cultura escrita e de apropriação da língua materna pode ocorrer dentro de um trabalho pedagógico intencionalmente planejado com os gêneros discursivos. Os gêneros do discurso são "tipos relativamente estáveis de enunciados", que, produzidos nas diferentes esferas de utilização da língua, organizam o discurso; em outras palavras, em cada esfera de atividade social, os falantes utilizam a língua de acordo com gêneros específicos (BAKHTIN, 2003). Sem eles, a comunicação seria praticamente impossível, pois a língua só pode se manifestar pelo gênero. Como a variedade da atividade humana é cada vez maior, a diversidade dos gêneros também se amplia e se transforma, na medida em que essa atividade se desenvolve e se amplia (BAKHTIN, 2003).

Desse modo, os gêneros discursivos são estáveis e mutáveis, ao mesmo tempo. São estáveis, porque conservam traços que os identificam, e são mutáveis, porque estão em constante transformação, pois se dão nas trocas, na relação com o outro, alterando-se a cada vez que são empregados, a ponto de haver casos em que um gênero se transforma em outro (SOBRAL, 2009, p. 115).

Há alguns aspectos dentro do caráter estável-dinâmico dos gêneros que precisam ser considerados. O gênero possui uma lógica orgânica, em outras palavras, não há algo que venha de fora se impor a ele, mas uma "ação generificante, criadora de suas características como gênero" (SOBRAL, 2009, p. 117). O gênero tem certo "tom", certa "linguagem", que não devem ser confundidos com fórmulas fixas, ainda que alguns gêneros possam ser "formulaicos" (SOBRAL, 2009, p. 117). Além disso, a lógica dos gêneros não é abstrata, porque se manifesta em cada variedade nova, em cada nova obra, e, portanto, o gênero não é rígido em sua normatividade, mas dinâmico e concreto. "O gênero traz o novo (a singularidade, a impermanência) articulado ao mesmo (a generalidade, a permanência), porque 
não é uma abstração normativa, mas um vir-a-ser concreto cujas regras supõem uma dada regularidade e não uma fixidez" (SOBRAL, 2009, p. 117-8).

Essas ideias sobre o conceito de gêneros do discurso se vinculam ao movimento com uma percepção global da arquitetônica bakhtiniana, em que é desenvolvida a compreensão sobre totalidade-estabilidade, na qual a relativa estabilidade de um gênero estaria relacionada a sua historicidade (memória do passado). Os enunciados e seus tipos, ou seja, os gêneros discursivos "são o retrato dos usos já feitos anteriormente, em várias atividades humanas, e são a memória e o acúmulo da história de suas utilizações" (GEGe, 2009, p. 50, grifos dos autores). Disso se depreende que os enunciados se constituem gradativamente em tipos e formas mais consistentes para uso em esferas específicas, com estilos específicos, temas específicos e, assim, se compõem com formas específicas. Esses enunciados relativamente estáveis se constituem, ainda, "como lugar de emergência dos sentidos históricos das comunicações existentes em determinados contextos e com determinadas significações" e também mantêm vivas aquelas significações já socialmente consolidadas (GEGe, 2009, p. 50).

O conceito de gênero discursivo, dentro da concepção bakhtiniana, requer igualmente que se desenvolva a compreensão sobre a singularidade-instabilidade. Essa compreensão se vincula à possibilidade de os gêneros estarem sempre em movimento, se atualizarem, se modificarem. Isso se deve ao fato de os gêneros serem criados nas relações sociais, de o sujeito ter sempre uma atitude responsiva e de esse trabalho responsivo instabilizar o gênero a cada vez que determinado enunciado é empregado, em determinada atividade humana. Cabe lembrar que o gênero é uma categoria discursiva, da ordem do enunciado.

Essa afirmação se encontra em consonância com a tese segundo a qual as crianças se apropriam da língua escrita por meio dos gêneros discursivos, quando estes são apresentados a elas pelo professor, de sorte a levá-las a interagir e a estabelecer relações intensas com eles. Essa tese se fundamenta na premissa de que "o emprego da língua efetua-se em forma de enunciados (orais e escritos) concretos e únicos, proferidos pelos integrantes desse ou daquele campo da atividade humana" (BAKHTIN, 2003, p. 261). A comunicação humana só é possível porque dominamos os gêneros empregados naquela atividade verbal.

E quanto mais os dominamos, mais livres nos sentimos no seu uso - um uso que é também renovação pelos diálogos com outros gêneros - e nas 
construções de sentidos possíveis que nosso projeto de dizer possibilita no jogo com o outro que também se comunica comigo. (GEGe, 2009, p. 52).

Ao considerar esses pressupostos, afirma-se que é desde a Educação Infantil que a apresentação e o ensino de diferentes gêneros discursivos podem ocorrer de modo dialógico, uma vez que as crianças são capazes de aprender a ter uma atitude responsiva, de refletir, refratar ou refutar aquilo que veem, ouvem, percebem, pensam - e essa atitude diante do conhecimento, da leitura e da escrita contribuirá para que elas se constituam como leitoras e re-criadoras de textos.

Para Bakhtin (2003), os gêneros se dividem em dois grupos: gêneros primários e gêneros secundários. Os gêneros primários são considerados mais simples em sua composição, são mais cotidianos, "se formam nas condições da comunicação discursiva imediata" (BAKHTIN, 2003, p. 263). Os gêneros secundários são mais complexos, mais elaborados, "surgem nas condições de um convívio cultural mais complexo e relativamente mais desenvolvido e organizado" (BAKHTIN, 2003, p. 263) e se estabelecem "como relacionais entre si, numa troca infinita de sentidos e renovando continuamente os gêneros" (GEGe, 2009, p. 52). Os gêneros discursivos secundários, em seu processo de formação, incorporam e reelaboram os diversos gêneros primários. Esses gêneros primários, por sua vez, integram os complexos: "aí se transformam e adquirem um caráter especial: perdem o vínculo imediato com a realidade concreta e os enunciados reais alheios" (BAKHTIN, 2003, p. 263).

Os gêneros discursivos possuem três elementos - o conteúdo temático, o estilo e a construção composicional. Esses três elementos estão indissoluvelmente ligados no todo do enunciado e são igualmente determinados pela especificidade de um certo campo da comunicação (BAKHTIN, 2003).

\section{A CRIANÇA E O SEU ESTATUTO DE LEITOR E DE RE-CRIADOR DE GÊNEROS DISCURSIVOS}

Este artigo compreende a leitura em seu movimento discursivo, isto é, a leitura como um lugar privilegiado de encontro com a palavra alheia. Essa concepção de leitura advém do conceito de língua e de linguagem, para Bakhtin (1992), em que a língua é um fenômeno social dirigido para o outro. Disso decorre que não há diálogo entre sentenças, mas entre pessoas. Existe infinita mobilidade para diferentes interpretações e significações que tornam a palavra permanentemente fluida, no contexto das transformações culturais e históricas. 
Conforme Bakhtin (1992), a categoria principal da linguagem é a interação verbal, cuja realidade fundamental é o seu caráter ideológico. Toda enunciação é um diálogo, e faz parte de um processo de comunicação ininterrupto. Desse modo, a interação verbal se realiza no diálogo, o qual, em sentido mais amplo, ocorre na leitura e na escrita. O caráter ideológico do diálogo remete ao contexto histórico e cultural, uma vez que os diálogos e os discursos são envolvidos pelos interesses, pelos valores e pelas intenções definidas por um grupo ou classe social, em dado tempo.

A linguagem tem dimensões dialógicas e ideológicas determinadas historicamente. A palavra, território comum entre eu e o outro (locutor/interlocutor), é prenhe de significados e intenções (BAKHTIN, 1992), possui valor semiótico, sendo percebida como um signo ideológico: "arena de confronto de diferentes valores sociais, de diferentes vozes sociais" (RAMOS; SHAPPER, 2009). Por essa razão, o sujeito se constitui discursivamente, ao interagir com as vozes sociais as quais constituem a comunidade semiótica de que participa. Essas vozes, em inter-relação dialógica, possibilitam encontro entre consciências, marcado por movimentos de sentidos que "ora instituem a reprodução do discurso alheio, ora possibilitam que ele se abra para novas construções discursivas" (RAMOS; SHAPPER, 2009, p. 2).

No movimento de produção e negociação de sentido que demarca a leitura como prática social e cultural, faz-se necessário compreender as formas de discurso que relacionam a palavra do leitor à palavra alheia, expressa no texto, já que o sujeito fala por meio da palavra dos outros e todo enunciado é uma réplica de um diálogo que incorpora e se apropria do discurso de outrem. Os enunciados são sempre dependentes daquilo que já foi dito e só podem ser compreendidos no fluxo da cadeia de interação verbal. A palavra é, por assim dizer, dialógica, pois pressupõe o outro, pressupõe em si mesma uma resposta.

A leitura na perspectiva bakhtiniana da teoria enunciativa da linguagem traz uma entonação outra ao universo da relação do leitor com o texto. A percepção dialética da linguagem preconizada pelo autor permite pensar a leitura como produção de sentido, instância discursivo-simbólica mediadora das relações entre sujeitos. Nesse panorama teórico, Bakhtin (1983) explicita dois tipos de palavras alheias que adquirem um sentido fundamental, no processo de formação ideológica do homem no mundo: a palavra de autoridade e a palavra internamente persuasiva. Por meio desses termos, o autor objetiva mostrar a complexidade 
do processo de apropriação linguístico-discursiva, o qual não se funda somente na repetição e no reconhecimento da palavra alheia, mas em sua reelaboração, repercutindo de modo diferente e sob uma nova perspectiva. Assim, se, de um lado, há discursos assumidos como vozes de autoridade, por outro, há discursos que são assumidos como vozes internamente persuasivas.

O discurso autoritário se estabelece no estatuto de verdade plena, absoluta, e consolida-se ou reforça significados fixos que não se modificam em contato com outras vozes. Por ser vinculado à autoridade (moral, política, religiosa, paterna, do professor), é encontrado ao exigir do homem o seu reconhecimento incondicional. Além disso, a palavra de autoridade se materializa no discurso proferido, não existindo espaço para argumentação, refutação ou contestação, porque "a palavra autoritária não se representa - ela é apenas transmitida" (BAKHTIN, 1983, p. 144).

Em contraposição ao discurso de autoridade, a palavra internamente persuasiva não é finita nem rígida, mas se abre para muitas possibilidades de inferência no discurso interior. É dialógica, carrega em si parte da palavra própria e parte da palavra do outro, e, em decorrência disso, propicia negociações de significados, encadeando a produção de novos sentidos.

Conforme exposto, a linguagem é algo vivo, mutável e está em constante movimento, porque se dá nas relações, na troca, na atitude responsiva. A leitura, nesse contexto, é concebida como um processo dialógico e dinâmico e o ensino do ato de ler numa perspectiva que considera a responsividade, a palavra internamente persuasiva e, por assim dizer, coloca constantemente a criança em diálogo com o texto e com o outro. A atitude responsiva na leitura requer a compreensão ativa e, segundo Bakhtin (1992, p. 131-2), "qualquer tipo genuíno de compreensão ativa deve conter já o germe de uma resposta. Só a compreensão ativa nos permite apreender o tema, pois a evolução não pode ser aprendida senão com a ajuda do outro processo evolutivo".

É nesse contexto das relações dialógicas que a leitura e a escrita se situam. Ler é compreender, é produzir sentido, é uma prática social, histórica e cultural (ARENA, 1992; 2010). Ler é dialogar com o texto, é questioná-lo, é construir e reconstruir o texto, no interior do pensamento, instaurando relações ativas e dinâmicas com ele. Durante a leitura, o sujeito leva em consideração o discurso do outro que estará sempre presente no seu. A leitura ocorre na atividade da própria língua, em seu uso nas relações sociais, na interação do escritor com o 
leitor, na palavra interna persuasiva. Nessa perspectiva - perspectiva defendida neste trabalho -, a leitura é um objeto da cultura e, como tal, precisa ser ensinada às crianças como algo que se contraponha ao ensino da leitura de forma estática, acabada em si mesma, que nada refuta, nada reflete, nada refrata e que reduz o discurso escrito a um compilado de letras, sílabas, palavras e frases, portanto, o não discurso. Quando a criança dialoga com o texto, atua nele e tem uma atitude responsiva, ela assume para si o estatuto de leitor. O mesmo acontece com a escrita. O que orienta a apropriação da escrita são as relações dialógicas que a criança estabelece com ela, por meio das mediações e situações promotoras de aprendizagem.

Ler e escrever são atividades altamente complexas que envolvem o conhecimento de linguagens sociais (BAKHTIN, 1983, p. 154-5), as quais, histórica e culturalmente, foram organizadas oralmente e por escrito, por meio de recursos expressivos, como modos de dizer os conhecimentos das diferentes esferas sociais criadas pelo homem. As linguagens sociais apresentam os conhecimentos específicos em cada esfera de atividade humana, com sintaxes e repertórios lexicais que as caracterizam, relacionadas aos gêneros do discurso que foram se elaborando para contemplar as necessidades humanas nas situações sociais (GOULART, 2006).

Criar textos com as crianças e ensiná-las a re-criar os seus próprios é garantir que elas possam expressar ideias, sentimentos, escolhas, opiniões, e a operar com os signos. É no texto que a língua se manifesta, que se revela na sua totalidade, seja como conjunto de formas, seja como discurso que remete a uma relação intersubjetiva constituída no próprio processo de enunciação marcada pela temporalidade e suas dimensões (GERALDI, 2003). Não há texto sem o outro, sem um interlocutor.

De acordo com Bakhtin (2003, p. 307), "o texto é a realidade imediata (realidade do pensamento e das vivências) [...] onde não há texto não há objeto de pesquisa e pensamento". A re-criação de texto, nessas condições, se configura como um processo carregado de historicidade, construído pelos sujeitos em diferentes momentos e condições de interação que expressam ideias, opiniões, desejos. Um processo interativo discursivo que põe em jogo os conhecimentos já apropriados sobre a língua e cria a necessidade de novas apropriações. Nesse processo, a criança atua como sujeito, e não como objeto. Ela participa intensamente do discurso e, de forma ativa, é capaz de dialogar com o outro, tornando-se 
também parceira num ato comunicativo. Quando isso acontece, a criança assume o estatuto de re-criador de textos.

Entre as muitas situações de leitura e de escrita de gêneros discursivos proporcionadas pela minha atuação como professora de uma turma de crianças de cinco e seis anos da Educação Infantil, de uma escola pública municipal do município de Marília, SP, as quais fizeram parte da minha pesquisa, será apresentada uma delas, neste tópico, acompanhada de análises amparadas pelos princípios teóricos até aqui expostos. A situação em pauta enfoca a re-criação de um relato escrito no livro da vida da turma. O livro da vida é um compilado de registros escritos dos acontecimentos mais significativos da turma. São as crianças que dizem o que deve ser escrito no livro da vida, e esses registros foram feitos por mim, porque as crianças não eram, no início do trabalho, convencionalmente alfabetizadas. Os textos re-criados no livro da vida eram em grande parte coletivos - quando se referiam às vivências do grupo - ou individuais - quando eram assuntos pessoais, dos quais as próprias crianças solicitavam o registro.

Após a roda da conversa ${ }^{4}$ em que as crianças se dividiram para realizar suas tarefas nos ateliers ou cantos de trabalho, uma criança se dirige a mim e diz:

Criança: Pro, sabe o que eu contei na roda da conversa?

Professora: Sim, sei sim...

Criança: Eu quero escrever no livro da vida.

Professora: E por que você quer escrever o que você contou hoje na roda da conversa no livro da vida?

Criança: Porque todo mundo vai ler, até a minha mãe, quando ela vier na reunião (refere-se à Reunião de Pais e Mestres que ocorre periodicamente, na escola).

Atendi ao pedido da criança e iniciamos a re-criação do seu relato de vida.

Professora: Muito bem, então vamos começar?

Criança: Vamos.

Professora: Como você quer começar seu texto?

\footnotetext{
${ }^{4}$ A roda da conversa é um momento em que crianças e professora, isto é, todo o grupo, apresentam novidades, planejam o que farão no dia, negociam situações, resolvem problemas, discutem assuntos diversificados sobre o que vivem, sobre o que veem, sobre o que sentem, comentam sobre os estudos e pesquisas, contam curiosidades, planejam, avaliam e redirecionam o trabalho. Por essas razões, a roda confere a todos os participantes do grupo - e especialmente às crianças - o direito de falarem e de serem ouvidos por todo o coletivo, dando a palavra a cada um dos membros.
} 
Criança: Primeiro a data, pro.

[Então, escrevo a data: "Marília, 4 de junho de 2010"].

Professora: E agora?

Criança: Pode escrever assim, ó: "Ontem eu fui de ônibus com a minha mãe na casa da minha tia".

[Eu escrevo o que a criança diz e, em seguida, ela me indaga].

Criança: Pro, por que você não começou a escrever grudadinho no começo da folha?

Professora: Porque esse pequeno espaço mostra que estamos iniciando um parágrafo, uma ideia que começa a ser escrita.

Criança: Hum...

Professora: Bem, o que mais será colocado aqui?

Criança: É... escreve assim, pro: "No caminho, eu vi o lugar onde o meu pai trabalha, que é a DORI (refere-se a uma fábrica de doces). É tão grande! E também vi a fumacinha do lugar onde o meu tio trabalha, que é na BEL".

Professora: O que é a BEL? Acho que é melhor explicar, porque nem todas as pessoas que vão ler o texto sabem o que é a BEL, e Bel pode ser a abreviação do nome de uma pessoa, de Isabel, um apelido carinhoso para quem tem esse nome.

Criança: É uma fábrica de doces.

[Escrevo o que a criança sugeriu].

Professora: Bem, o que mais você quer escrever?

Criança: "Aí, quando eu vim embora, eu vi na loja uma boneca no balanço e eu pedi para a minha mãe comprar ela pra mim, no dia do meu aniversário". [Então, escrevo o que a criança diz, e ela me interrompe].

Criança: Pro, tem um monte de espaço que sobrou na frente de onde você estava escrevendo! Por que você escreveu embaixo? Olha aí, ó... [Aponta o indicador direito para a folha em que eu escrevia].

Professora: Por que você acha que eu escrevi embaixo e não na frente, até preencher o espaço?

Criança: Ah... por quê? Hum... [C6 observa o que foi escrito, dirige o olhar para o teto... silencia por alguns segundos]. Ai, eu não sei...

Professora: Eu comecei embaixo escrevendo grudadinho no começo da folha ou eu deixei um espaço para indicar um novo parágrafo?

Criança: Deixou espaço e começou um novo parágrafo.

Professora: Hum... e por que será que eu fiz isso?

Criança: Ai, eu não sei direito, mas eu vou contar agora outra parte do meu passeio.

Professora: Isso mesmo, e por ser outra parte do seu passeio, por ser outra ideia que você está dizendo, eu comecei outro parágrafo para organizar tudo melhor. 
Criança: Ah, tá... entendi...

Professora: Então, vamos retomar a sua ideia. [Releio o que eu havia escrito até aquele momento e 66 continua].

Criança: Só falta escrever assim, pro: "Mas ela disse que eu já tenho bonecas demais".

Terminada a escrita do relato de vida dessa criança, organizei com as demais rapidamente a sala, para que outra professora pudesse ocupá-la com sua turma, e dirige-me com as crianças ao refeitório, porque já estávamos alguns minutos atrasados para o lanche. As crianças se acomodaram no refeitório, e percebi que a que acabara de re-criar o texto não estava junto à turma para lanchar. Solicitei a uma funcionária que pudesse atender àquelas que ali estavam e fui à sua procura. Voltei à sala que momentos antes ocupávamos e encontrei a criança escrevendo seu nome no texto que acabara de re-criar. Permaneci em silêncio e, assim que terminou de escrever seu nome no texto, a criança me explica:

Criança: Eu não podia ir para o lanche sem escrever o meu nome no texto, pro. Professora: Que bom que você se lembrou de fazer isso!

Criança: Eu tinha que escrever meu nome para todo mundo saber que fui eu quem fiz. A ilustração eu faço amanhã, tá? Eu só queria escrever o meu nome no meu texto.

Professora: Combinado. Amanhã você faz a ilustração do seu texto. [A criança então, guardou o livro da vida no armário e fomos juntas para o refeitório].

Pela análise da situação apresentada, a criança aparenta perceber que a escrita legitima as coisas, que se escreve para que se possa ser lido e lembrado, em qualquer outro momento, e que se escreve porque se quer comunicar algo para um outro real, um destinatário real. Escreve porque tem a intenção de que o outro leia, porque quer se expressar. Isso se verifica quando a criança se direciona a mim e diz: "Eu quero escrever no livro da vida", e quando eu pergunto o motivo por que quer escrever no livro da vida, justifica: "Porque todo mundo vai ler, até a minha mãe quando ela vier na reunião".

É possível notar que a criança aprende a língua em movimento, na relação com o outro. Focalizar a linguagem a partir do processo interlocutivo (GERALDI, 2003) e, nessa perspectiva, pensar o processo educacional enquanto produção da linguagem e dos sujeitos significa admitir que a língua não está pronta e acabada (BAKHTIN, 1992), mas que o próprio processo interlocutivo na atividade da 
linguagem (re)constrói os sujeitos que a constituem, à medida que interagem uns com os outros. O sujeito "mergulhado nas múltiplas relações e dimensões da interação socioideológica, vai se constituindo discursivamente, assimilando vozes sociais e, ao mesmo tempo, suas inter-relações dialógicas (FARACO, 2009, p. 84). Por essa razão é que, figurativamente, Bakhtin afirma "que não tomamos nossas palavras do dicionário, mas dos lábios dos outros" (FARACO, 2009, p. 84).

Um aspecto a ser ressaltado é que a criança se reconhece como autora, como a re-criadora do texto, como alguém que sabe escrever, mesmo que naquela ocasião ainda não escrevesse convencionalmente sem a ajuda da professora que atuou como escriba. Pode-se perceber, desde o início da conversa, quando solicita que quer "escrever" no livro da vida o que havia contado na roda da conversa, e na situação final, em que volta para a sala a fim de assinar o texto re-criado, enquanto toda a turma se encontrava no refeitório para o lanche. Desse modo, pode-se ressaltar:

Por autor o Círculo designa não somente o autor de obras literárias ou não, mas também o autor de enunciados, o que se justifica se pensarmos que, embora reconhecendo a especificidade dos discursos aos quais se costuma atribuir um autor, o Círculo considera os atos de discurso parte do conjunto dos atos humanos em geral - e todo agente de um ato humano é, nesse sentido, "autor" de seus atos. Assim, falar de autor no âmbito das teorias do Círculo implica pensar no contexto de ação dos sujeitos, e nas complexas tarefas que realizam ao enunciar. Implica considerar, como afirmei alhures, de um lado, o princípio dialógico (que segue a direção do interdiscursivo, da relação com o outro) e, do outro, os elementos sociais, históricos, etc. que formam o contexto da interação e que incidem sobre a ação autoral. Trata-se de elementos que estão contidos na própria superfície dos discursos, e que só aí nos são acessíveis, mas que não se esgotam nessa superfície. (SOBRAL, 2009, p. 61-2).

A criança revela a necessidade de escrever seu nome no texto, para que as pessoas que o lessem, soubessem que se tratava de uma re-criação sua. A criança denota, por sua atitude e por sua fala, que a escrita se torna gradativamente, para ela, uma necessidade. Por essa razão, diz: "Eu tinha que escrever meu nome para todo mundo saber que fui eu quem fiz", "Eu só queria escrever o meu nome no meu texto". Pode-se inferir também que, para a criança, a escrita do seu próprio nome garante a sua autoria. Por isso, voltar para escrevê-lo naquele momento, não deixando para o dia posterior, se constitui como fundamental, uma vez que o 
desenho, a ilustração do texto re-criado, comumente realizada pelas crianças em todos os textos re-criados, possivelmente não se apresentou crucial como a escrita para essa criança, nessa situação, ao dizer: "A ilustração eu faço amanhã, tá?"

Por meio da re-criação do gênero discursivo, as crianças aprendem a língua de forma dinâmica, aprendem a pensar sobre ela e sobre o seu funcionamento de maneira responsiva. Pela relação dialógica estabelecida entre a criança e a professora, no caso, eu mesma, a criança, no processo inicial de apropriação da escrita, pensa sobre a ideia, o conceito de parágrafo e, principalmente, a sua função no texto.

Pode-se dizer que a criança aprende a pensar a língua em movimento, uma língua viva, que está presente nas relações estabelecidas, e não como uma língua morta, vazia, em que nada se pode refletir, refratar ou refutar. As crianças, apesar de pequenas, são capazes de aprender a língua dialogicamente, quando as situações de ensino e de aprendizagem são planejadas intencionalmente, são reais e acontecem num contexto dialógico, interlocutivo.

Aspectos da gramática, da ortografia, são abordados com as crianças, devido às situações que surgem no processo de re-criação dos gêneros discursivos e, geralmente, em função da minha mediação como professora e da observação das próprias crianças que vivem frequentemente situações de escrita e de leitura dos gêneros discursivos.

Ao pensar no destinatário real, ressalta-se que eu, a professora, solicito que a criança explicite o que é "BEL", porque, apesar de as pessoas que moram na cidade em que se fez a pesquisa terem mais provavelmente conhecimento do que seja "BEL", o objetivo era que a criança pudesse se fazer entender por qualquer e todo leitor. Em outras palavras, que ela, em qualquer situação de escrita, de re-criação, possa estabelecer uma relação responsiva, um diálogo com o outro, com o leitor, seja ele quem for. Que a criança possa compreender a palavra alheia, mas que possa permitir que o outro compreenda ativamente a sua palavra, visto que, para Bakhtin (1992, p. 131-2), "compreender a enunciação de outrem significa orientar-se em relação a ela, encontrar o seu lugar adequado no contexto correspondente". 


\section{CONCLUSÃO}

Muitas vezes, no cotidiano da escola da pequena infância e no ensino da língua materna, são apresentados alguns poucos gêneros discursivos às crianças, em geral, os contos narrativos. Ocorre ainda que, quando são expostos, se constituem como um conjunto de propriedades formais isolado da esfera de ação. Os gêneros, nessas condições, aparecem como objetos didáticos, e não como instrumento de comunicação, o que contradiz os pressupostos teóricos, defendidos neste trabalho, de que os gêneros discursivos requerem que sejam vistos na sua função de interação, porque são a realidade da comunicação humana, são instrumentos que tornam possível a comunicação discursiva (BAKHTIN, 2003). Novos modos de ver e de conceituar a realidade implicam o aparecimento de novos gêneros e alteração dos já existentes (FIORIN, 2006).

As crianças, desde pequenas, são capazes de estabelecer relações intensas com a leitura e a escrita, por meio dos gêneros discursivos, quando aprendem a usar a língua em diferentes situações, quando ela não chega às crianças de forma pronta, acabada, pois, do contrário, se sentem provocadas a pensar sobre ela, em sua dialogicidade, em movimento, para que possam cada vez mais dispor dela quando, onde e como queiram.

Os gêneros requerem que sejam ensinados desde a Educação Infantil, num contexto interativo e dinâmico, porque, se não se der nessas condições, eles perdem a função para a qual se destinam: a função de expressar, de interagir, de comunicar. E, dessa maneira, assumem o papel de objeto didático. Quando isso acontece, deixam de ser gêneros discursivos, porque perdem sua essência flexível, dialógica, mutável e, consequentemente, as crianças não conseguem se utilizar deles, nos diversos contextos sociais e discursivos. Por uma ação docente intencional, dinâmica e dialógica, elas percebem o conteúdo temático, a construção composicional e o estilo de cada gênero, objetivando-se pelos discursos que expressam seus pensamentos, impressões e opiniões. Elas iniciam o conhecimento da estrutura da língua, em seus diferentes aspectos - gramática, ortografia, coerência, coesão, por exemplo -, pelo uso e reflexão desse uso e não por exercícios impostos de memorização, repetição, nem por exercícios motores de coordenação.

A criança inicia o processo de internalização da língua pelas relações que ela estabelece com a própria língua, em seu funcionamento, com a professora, 
com os colegas, com os materiais, com os gêneros discursivos. A leitura e a escrita nascem do desejo de expressão criado na criança, pelas condições de vida e de educação das quais participa (LEONTIEV, 1978).

\section{REFERÊNCIAS}

ARENA, D. B. O ensino da ação de ler e suas contradições. Ensino Em-Revista, Uberlândia, v. 17, n. 1, p. 237-47, jan./jun. 2010.

. Bakhtin e alfabetização. Educação, Santa Maria, RS, v. 17, p. 71-89, 1992.

BAKHTIN, M. Estética da criação verbal. São Paulo: Martins Fontes, 2003.

. Marxismo e filosofia da linguagem. 5. ed. Tradução de Michel Lahud e Yara Frateschi Vieira. São Paulo: Hucitec, 1992.

. Questões de Literatura e de Estética: a teoria do romance. 3. ed. São Paulo: Hucitec/UNESP, 1983.

BISSOLI, M. de F. Leitura e escrita na Educação Infantil: uma aproximação entre a Teoria Histórico-Cultural e as técnicas Freinet. In: CONGRESSO DE LEITURA DO BRASIL-COLE, 17., 20-24 jul. 2009, Campinas, SP. Anais... Campinas: UNICAMP, 2009. Disponível em: $<$ http://alb.com.br/arquivo-morto/edicoes_anteriores/anais17/txtcompletos/sem13/ COLE_4037.pdf>. Acesso em: 4 maio 2012.

FARACO, C. A. Linguagem \& diálogo: as ideias lingüísticas do Círculo de Bakhtin. São Paulo: Parábola, 2009.

FIORIN, J. L. Introdução ao pensamento de Bakhtin. São Paulo: Ática, 2006.

GERALDI, J. W. Portos de passagem. São Paulo: Martins Fontes, 2003.

GOULART, C. M. A. Letramento e modos de ser letrado: discutindo a base teóricometodológica de um estudo. Revista Brasileira de Educação, Campinas, v. 11, n. 33, p. 450-60, set./dez. 2006.

GRUPO DE ESTUDOS DOS GÊNEROS DO DISCURSO (GEGe). Palavras e contrapalavras: conversando sobre os trabalhos de Bakhtin. 1. ed. São Carlos: Pedro \& João, 2010.

. Palavras e contrapalavras: glossariando conceitos, categorias e noções de Bakhtin. São Carlos: Pedro \& João, 2009.

LEONTIEV, A. N. O desenvolvimento do psiquismo. Tradução de Manuel Dias Duarte. Lisboa: Horizonte Universitário, 1978.

MIOTELLO, V. et al. Diálogos Ponzianos... Encontros com palavras outras. In: PONZIO, A. Dialogando sobre diálogo na perspectiva bakhtiniana. São Carlos: Pedro \& João, 2012. p. 7-12. 
RAMOS, B. S.; SHAPPER, I. O encontro do leitor com a palavra alheia: leituras bakhtinianas. Revista Teias, Rio de Janeiro, v. 10, n. 19 [Sujeitos, espaços educativos \& processos de comunicação], p. 1-7, 2009. Disponível em: <http://www.periodicos.proped.pro.br/index. php?journal=revistateias \&page=article\&op=viewFile\&path\%5B\%5D=330\&path\%5B\% 5D=356>. Acesso em: 12 ago. 2012.

SOBRAL, A. Do dialogismo ao gênero: as bases do pensamento do círculo de Bakhtin. Campinas, SP: Mercado de Letras, 2009. (Série ideias sobre linguagem).

\section{Sobre a autora:}

Greice Ferreira da Silva: Doutora em Educação Brasileira pela Universidade Estadual "Júlio de Mesquita Filho". Docente da Universidade Estadual de Londrina. E-mail: grebalet@terra.com.br

\section{Recebido em fevereiro de 2018}

Aprovado em maio de 2018 